\title{
BMJ Open In which groups of pregnant women can the caesarean delivery rate likely be reduced safely in the USA? A multicentre cross-sectional study
}

\author{
Jin-Wen Zhang, ${ }^{1,2}$ Ware Branch, ${ }^{3}$ Matthew Hoffman, ${ }^{4}$ Ank De Jonge, ${ }^{5}$ \\ Sheng-Hui Li, ${ }^{1,2}$ James Troendle, ${ }^{6}$ Jun Zhang ${ }^{1,2}$
}

To cite: Zhang J-W, Branch W, Hoffman M, et al. In which groups of pregnant women can the caesarean delivery rate likely be reduced safely in the USA? A multicentre crosssectional study. BMJ Open 2018;8:e21670. doi:10.1136/ bmjopen-2018-021670

- Prepublication history and additional material for this paper are available online. To view these files, please visit the journal online (http://dx.doi org/10.1136/bmjopen-2018021670).

Received 22 January 2018 Revised 19 May 2018 Accepted 18 June 2018

Check for updates

(C) Author(s) (or their employer(s)) 2018. Re-use permitted under CC BY-NC. No commercial re-use. See rights and permissions. Published by BMJ.

For numbered affiliations see end of article.

\section{Correspondence to}

Dr Sheng-Hui Li;

Ish9907@163.com and Dr Jun

Zhang;

junjimzhang@sina.com

\section{ABSTRACT}

Objectives To identify obstetrical subgroups in which (1) the caesarean delivery $(\mathrm{CD})$ rate may be reduced without compromising safety and (2) CD may be associated with better perinatal outcomes.

Design A multicentre cross-sectional study.

Setting 19 hospitals in the USA that participated in the Consortium on Safe Labor.

Participants 228562 pregnant women in 2002-2008. Main outcome measures Maternal and neonatal safety was measured using the individual Weighted Adverse Outcome Score.

Methods Women were divided into 10 subgroups according to a modified Robson classification system. Generalised estimated equation model was used to examine the relationships between mode of delivery and Weighted Adverse Outcome Score in each subgroup. Results The overall caesarean rate was $31.2 \%$. Repeat CD contributed $29.5 \%$ of all CD, followed by nulliparas with labour induction (15.3\%) and non-cephalic presentation (14.3\%). The caesarean rates in induced nulliparas with a term singleton cephalic pregnancy and women with previous CD were $31.6 \%$ and $82.0 \%$, respectively. CD had no clinically meaningful association with perinatal outcomes in most subgroups. However, in singleton preterm breech presentation and preterm twin gestation with the first twin in non-cephalic presentation, CD was associated with substantially improved maternal and perinatal outcomes. Conclusions Women with repeat $\mathrm{CD}$, term non-cephalic presentation, term twins or other multiple gestation and preterm births may be the potential targets for safely reducing prelabour $\mathrm{CD}$ rate, while nulliparas or multiparas with spontaneous or induced labour, women with repeat $\mathrm{CD}$, term non-cephalic presentation, term twins or other multiple gestation and preterm births are potential targets for reducing intrapartum $C D$ rate without compromising maternal and neonatal safety in the USA. On the other hand, CD may still be associated with better perinatal outcomes in women with singleton preterm breech presentation or preterm twins with the first twin in noncephalic presentation.

\section{INTRODUCTION}

In the past decade, the rate of caesarean delivery (CD) in the USA has remained above
Strengths and limitations of this study

- The Consortium on Safe Labor is one of the largest and most comprehensive perinatal database so far with clinical data from a contemporary population, which enabled us to examine the relationships between mode of delivery and Weighted Adverse Outcome Score in 10 mutually exclusive subgroups and adjust for a number of confounding factors.

- Since this is an observational study, associations reported in our analysis may not necessarily be causal.

- Although confounding by other variables was carefully considered, residual confounding cannot be excluded.

$30 \%,{ }^{1}$ and this trajectory appears likely to continue in the near future. High CD rates may be associated with unnecessary utilisation of health resources ${ }^{2}$ and result in potential maternal and neonatal harm. ${ }^{34}$

Recent data suggested that $\mathrm{CD}$ rates below $20 \%$ at the population level are possible, safe and compatible with optimal health outcomes for mothers and their newborns. ${ }^{5} 6$ For instance, the Netherlands has had a stable, relatively low CD rate (14.0\% in 2000-2001 and $16.7 \%$ in $2010^{7}$ ) while maintaining good maternal and perinatal outcomes. ${ }^{89}$ However, at the level of an individual health facility, it is often difficult to determine an appropriate $\mathrm{CD}$ rate. Differences in casemix and obstetric profile prevent direct comparisons with a universal reference rate for CD. Based on data disaggregation in 10 obstetric groups, Robson proposed a classification system that facilitates the understanding of the internal structure of the CD rate at individual health facilities and identification of strategic population groups to prevent unnecessary $\mathrm{CD}{ }^{10}$

This study examined the associations of mode of delivery with adverse maternal and neonatal outcomes in the 10 subgroups of 
women in a large multicentre study. We aimed to identify (1) which groups contributed to the high overall $\mathrm{CD}$ rate, (2) in which groups the $\mathrm{CD}$ rate may be reduced safely and (3) in which groups CD may be associated with better perinatal outcomes.

\section{METHODS}

\section{Study population}

We used data from the Consortium on Safe Labor, a multicentre cross-sectional study that abstracted detailed labour and delivery information from electronic medical records in 19 hospitals across 9 American Congress of Obstetricians and Gynecologists (ACOG) US districts from 2002 to 2008. Eighty-seven per cent of births occurred in 2005-2007. Detailed description of the study is available elsewhere. ${ }^{11}$ There were a total of 228562 deliveries in the database. To avoid intraperson correlation, we selected the first delivery from each mother in the study $(90.5 \%)$. To make our study population reflect the overall US obstetric population and to minimise the impact of the various number of births from different hospitals, we first standardised the population using ACOG district, maternal race/ethnicity, parity and fetal plurality based on 2004 National Natality data. ${ }^{12}$ Then, based on the number of subjects each hospital contributed to the database, we assigned a weight to each subject. ${ }^{11}$ We applied the weight to the current descriptive analysis.

\section{Outcomes measures}

Perinatal outcomes were measured using the individual Weighted Adverse Outcome Score (WAOS), calculated as the sum of WAOSs of all events. ${ }^{13}$ The WAOS assigns a score of 750 for maternal death, 400 for intrapartum or in-hospital newborn death, 100 for uterine rupture, 65 for maternal intensive care unit admission, 60 for birth injury, 40 for unanticipated operative procedure, 35 for admission to neonatal intensive care unit for $>24$ hours, 25 for a 5 min Apgar score $<7,20$ for blood transfusion and 5 for 3 rd or 4 th degree perineal tear. The minimal score for any individual delivery is 0 while the maximum is 750 .

\section{Classification of labour management subgroups}

To identify sources of high CD rates and make appropriate comparisons in CD rates among hospitals or areas, we classified pregnant women into 10 mutually exclusive categories as described by Robson based on parity, gestational age, fetal presentation, number of fetuses, onset of labour and previous CD. ${ }^{10}$ Such a classification scheme has gained wide acceptance by the international obstetric and midwifery communities. ${ }^{14}$ In order to account for contemporary obstetric practices, we slightly modified the classification scheme, ${ }^{15}$ For instance, in groups 2 and $4,{ }^{10}$ induction of labour and prelabour CD was combined for nulliparous and parous women, respectively. This classification cannot differentiate between intrapartum CD after induction of labour and prelabour CD. As induction of labour and repeat CS before labour is now common, combining these two groups of women may miss important information regarding the success of induction and its contribution to a high CD rate. In addition, the Robson classification separated breech (by parity) and transverse or oblique lies into three groups $(6,7,9)$. Given that the total number of non-cephalic presentation births is small (around 4\%-5\%) and vaginal delivery is no longer promoted in many countries nowadays, these three groups may be combined into 1, so that the total number of subgroups remains 10 . The Robson classification labels subgroups by numbers (1-10). To make the group label more intuitive, we also proposed a new labelling scheme using only two letters (table 1 ).

\section{Statistical analysis}

In our study, $7.3 \%$ of pregnant women had missing information on fetal presentation. Given the importance of fetal presentation in the classification scheme, multiple imputation was performed where a logistic regression model imputed the likelihood of cephalic/non-cephalic presentation in a particular subject five times based on maternal race, parity, previous uterine scar, number of fetuses, external cephalic version, smoking, placenta previa, cephalopelvic disproportion, gestational age, reason for admission to labour/delivery, trial of labour, induction, fetal scalp electrode, operative vaginal delivery and mode of delivery. ${ }^{16}$ For the descriptive analysis, to reach one single number after multiple imputations, the mean of the five imputed values was used. ${ }^{16}$

For descriptive analyses that used a total population, no statistical testing was performed; nor were CIs calculated. To examine the linear associations of mode of delivery with adverse maternal and neonatal outcomes, we applied a generalised estimating equation model to account for correlations within each hospital. All models adjusted for a number of potential confounders wherever appropriate (see online supplementary file table $\mathrm{S} 1$ ). All analyses were performed using the SAS for Windows, V.9.4 (SAS Institute), with two-tailed tests and a significance level of $p<0.05$.

\section{Patient and public involvement}

Patients or public were not involved in the development of the research questions, design, recruitment and conduct of the study. There are no plans to disseminate the results of the research to study participants.

\section{RESULTS}

\section{CD pattern in the USA}

Table 1 and online supplementary figure S1 illustrate that the total CD rate in the USA was $31.2 \%$, and prelabour and intrapartum CD rates were $18.1 \%$ and $13.1 \%$, respectively. The repeat $\mathrm{CD}$ due to a previous CD (group PC) accounted for $11.2 \%$ of all deliveries and $29.5 \%$ of all CD. The CD rate in this group was $82.0 \%$, and the majority were prelabour CD. Nulliparas with labour induction (group NI) was the second 
Table 1 Modified classification and composition of caesarean delivery in the Consortium on Safe Labor of the USA, 2002$2008^{*}$

\section{Modified classification group labels (original group labels)†}

NS (1)
$\mathrm{NI}(2 \mathrm{a})$

$\mathrm{NC}(2 \mathrm{~b})$

MS (3)

MI (4a)

$\mathrm{MC}(4 \mathrm{~b})$

$\mathrm{PC}(5)$

BR $(6+7+9)$
Characteristics of the group

Nulliparous women with a single cephalic pregnancy, at $\geq 37$ weeks gestation in spontaneous labour

Nulliparous women with a single cephalic pregnancy, at $\geq 37$ weeks gestation who had labour induced

\section{Proportion of} all deliveries

(\%)

rate $(\%)$

Rate of

Nulliparous women with a single
cephalic pregnancy, at $\geq 37$ weeks
gestation, who had caesarean
delivery before labour

Multiparous women, without previous caesarean delivery, with a single cephalic pregnancy at $\geq 37$ weeks gestation in spontaneous labour

Multiparous women, without 15.3

6.7

6.7

3.3 previous caesarean delivery, with a single cephalic pregnancy at $\geq 37$ weeks gestation, who had labour induced

Multiparous women, without previous caesarean delivery, with a single cephalic pregnancy at $\geq 37$ weeks gestation, who had caesarean delivery before labour

Multiparous women, with at least one previous caesarean delivery with a single cephalic pregnancy at $\geq 37$ weeks gestation

1.6

100.0

0.0

5.0 20.5

3.1

3.1

2.1

(\%)

7.7

15.3

All women with a single breech,

4.8

11.2

82.0

11.8

29.5 transverse or other abnormal fetal presentation, including women with previous caesarean delivery

\begin{tabular}{|c|c|c|c|c|c|}
\hline TW (8) & $\begin{array}{l}\text { All women with multiple } \\
\text { pregnancies (eg, twins), including } \\
\text { women with previous caesarean } \\
\text { delivery }\end{array}$ & 3.4 & 66.6 & 15.2 & 7.3 \\
\hline
\end{tabular}

*See text for details on multiple imputation performed.

†The new labelling system corresponds well with the previous numbering system as follows: $1=\mathrm{NS}$ (nulliparous, spontaneous); $2 \mathrm{a}=\mathrm{NI}$ (nulliparous, induced); $2 \mathrm{~b}=\mathrm{NC}$ (nulliparous, caesarean); $3=\mathrm{MS}$ (multiparous, spontaneous); $4 \mathrm{a}=\mathrm{Ml}$ (multiparous, induced); $4 \mathrm{~b}=\mathrm{MC}$ (multiparous, caesarean); 5=PC (previous caesarean); 6, 7, 9 combined=BR (breech and other non-cephalic presentation); $8=$ TW (twin and other multiple pregnancies); 10=PT (preterm).

largest contributor to all CD (15.3\%), not only because this group had a high intrapartum CD rate $(31.6 \%)$ but also because this group accounted for $15.0 \%$ of all deliveries. Women with non-cephalic presentation (group BR) only accounted for $4.8 \%$ of all deliveries, but took up $14.3 \%$ of all CD. Among singleton preterm 
births (group PT), the CD rate was $35.6 \%$, which accounted for $12.4 \%$ of all CD.

\section{The association between mode of delivery and maternal and neonatal outcomes}

Table 2 shows that mode of delivery was not associated with the outcome in nulliparas with spontaneous onset of labour or induction (groups NS and NI) or preterm singleton births (group PT). In multiparas with spontaneous onset of labour or induction (groups MS and MI) or previous CD (group PC), CD had a slight but statistically significant association with the composite adverse outcome. However, the magnitude of the point estimates was quite small even though they reached statistical significance, thus, the clinical significance is questionable.

When we looked at women with breech presentation (group BR) as a whole, prelabour CD and intrapartum $\mathrm{CD}$ were both negatively associated with the adverse outcomes (prelabour CD ( $\beta=-28.31,95 \%$ CI -48.76 to -7.86), intrapartum CD $(\beta=-24.71,95 \%$ CI -43.56 to $-4.87)$ ). However, when we separated this group into preterm BR and term BR, strong negative associations were found only in preterm BR (prelabour CD $(\beta=-90.49$, $95 \%$ CI -133.58 to -47.40$)$, intrapartum CD $(\beta=-80.36$, $95 \%$ CI -121.33 to -39.39$)$ ) but not in term BR. For women with multiple gestation (group TW) as a whole, prelabour and intrapartum CD were both negatively associated with the adverse outcomes. Again, when we separated this group into preterm TW and term TW, no association was found in term TW. CD was modestly associated with a better outcome in preterm TW (prelabour CD $(\beta=-7.53,95 \%$ CI -14.62 to -0.45$)$, intrapartum CD $(\beta=-6.23,95 \%$ CI -11.51 to -0.94$))$. However, when we further stratified these twin gestations, we found that the protective effort was mainly due to the benefits of $\mathrm{CD}$ in preterm twins with the first twin in non-cephalic presentation (prelabour CD ( $\beta=-20.77,95 \% \mathrm{CI}-48.26$ to 6.71 ), intrapartum CD $(\beta=-20.00,95 \% \mathrm{CI}-43.06$ to -0.95$))$.

\section{DISCUSSION}

\section{Main findings}

Our study found that the top four contributors to the CD rate in the USA were repeat CD (group PC), nulliparas with labour induction (group NI), non-cephalic presentation (group BR) and preterm births (group PT). Based on the association between the mode of delivery and perinatal outcomes, groups PC, term BR, term TW (twins or other multiple gestation) and PT may be the potential targets for safely reducing prelabour CD rate, while groups NS (nulliparas with spontaneous labour), NI, MS (multiparas with spontaneous labour), MI (multiparas with labour induction), PC, term BR, term TW and PT are potential targets for reducing intrapartum $\mathrm{CD}$ rate. Groups $\mathrm{PC}$ and NI offer the greatest opportunity given their large contribution to the caesarean rate. On the other hand, CD may still improve perinatal outcomes in women with singleton preterm breech presentation or preterm twins with the first twin in non-cephalic presentation.

\section{Interpretation}

Repeat CD accounted for $29.5 \%$ of all CD. Among them, prelabour $\mathrm{CD}$ rate was $70.2 \%$. A recent review found that trial of labour after caesarean (TOLAC) in comparison to elective repeat CD, has significantly lower risk of maternal death, but the risk of transfusion, uterine rupture, and perinatal and neonatal mortality may be increased, and no difference was found in newborn respiratory conditions, hypoxic-ischaemic encephalopathy or asphyxia. ${ }^{17}$ Our study, which combined and weighted the adverse maternal and neonatal outcomes, did not find any benefits of prelabour $\mathrm{CD}$ in women with 1 or $\geq 2$ prior $\mathrm{CD}$. Thus, group PC may be an appropriate candidate for reducing the prelabour $\mathrm{CD}$ rate.

Two-thirds of women with previous $\mathrm{CD}$ are eligible for TOLAC, ${ }^{18}$ which is a safe choice in carefully selected patients. ${ }^{19}$ However, only $29 \%$ of US women attempt TOLAC versus $71 \%$ in the Netherlands, ${ }^{15}$ and the associated success rate for vaginal birth has declined. ${ }^{17}$ The Dutch experience showed that the rate of TOLAC over $70 \%$ and a successful VBAC rate of $75 \%$ appear to be achievable without compromising safety. ${ }^{15}$ Although the Dutch experience may not be totally reproducible in the USA, the large differences suggest that there is room for improvement.

A more fundamental approach is to safely prevent primary CD. Contemporary US data showed that a high percentage of intrapartum CD were performed before $6 \mathrm{~cm}$ of cervical dilation, particularly in nulliparas and induced labour. ${ }^{20}$ Allowing sufficient time for cervical change in early labour $(<6 \mathrm{~cm})$ may well serve to reduce the $\mathrm{CD}$ rate, particularly in labouring nulliparas and multiparas (groups NS, NI, MS and MI). The high CD rate in induced nullipara (group NI), which is the second largest contributor to the overall $\mathrm{CD}$ rate, might be because the patients were not given a sufficient trial of labour. Variations in the management of labour induction may also affect $\mathrm{CD}$ rates. ${ }^{21}$ Careful selection of patients and the method of induction may help to improve the success rate of induction.

Dynamic contrasts in the association between mode of delivery and perinatal outcomes were observed in term and preterm pregnancy in both singleton breech (group $\mathrm{BR}$ ) and non-cephalic multiple gestation (group TW).

Our study found that in term BR both prelabour and intrapartum $\mathrm{CD}$ had no association with the outcome. A recent review including randomised and observational studies showed that perinatal mortality and morbidity in the planned vaginal term breech delivery were significantly higher than with planned $\mathrm{CD}$, but the absolute risks were relatively low. ${ }^{22} \mathrm{~A}$ recent review showed that planned CD reduced perinatal or neonatal death as well as the composite outcome death or serious neonatal morbidity, at the expense of somewhat increased maternal morbidity. ${ }^{23}$ However, in a subset with 2-year follow-up, 
Table 2 The association between mode of delivery in subgroups and combined adverse maternal and neonatal outcomes by generalised estimated equation model

\begin{tabular}{|c|c|c|c|}
\hline \multirow{2}{*}{$\begin{array}{l}\text { Modified classification of caesarean } \\
\text { groups }{ }^{*}(\mathrm{~N}, \%)\end{array}$} & \multirow{2}{*}{$\begin{array}{l}\text { WAOS } \\
\text { Mean }\end{array}$} & \multirow{2}{*}{$\begin{array}{l}\text { Unadjusted model } \\
\beta(95 \% \mathrm{Cl})\end{array}$} & \multirow{2}{*}{$\begin{array}{l}\text { Adjusted model† } \\
\beta(95 \% \mathrm{Cl})\end{array}$} \\
\hline & & & \\
\hline \multicolumn{4}{|l|}{ Group NS (37 841, 20\%) } \\
\hline Vaginal delivery (32 259, 85\%) & 4.44 & Ref. & Ref. \\
\hline \multicolumn{4}{|l|}{ Group NI (30 892, 16\%) } \\
\hline \multicolumn{4}{|l|}{ Group NC (2851, 1.5\%) } \\
\hline Pre-labour CD (2851, 100\%) & 7.10 & - & - \\
\hline Vaginal delivery $(0,0 \%)$ & - & - & - \\
\hline \multicolumn{4}{|l|}{ Group MS (42 272, 22\%) } \\
\hline Intrapartum CD (2019, 7\%) & 7.02 & 3.57 (2.14 to 4.99$)$ & 1.95 (0.50 to 3.40$)$ \\
\hline Vaginal delivery (26 954, 93\%) & 3.45 & Ref. & Ref. \\
\hline \multicolumn{4}{|l|}{ Group MC $(1403,0.7 \%)$} \\
\hline Pre-labour CD $(1403,100 \%)$ & 9.34 & - & - \\
\hline Vaginal delivery $(0,0 \%)$ & - & - & - \\
\hline \multicolumn{4}{|l|}{ Group PC (overall) (17 289, 8.9\%) } \\
\hline Pre-labour CD (10 958, 63\%) & 4.83 & $0.96(-0.03$ to 1.94$)$ & 1.03 (0.03 to 2.03$)$ \\
\hline Intrapartum CD $(2353,14 \%)$ & 5.58 & 1.70 (0.37 to 3.03$)$ & 1.30 (0.28 to 2.32$)$ \\
\hline Vaginal delivery $(3978,23 \%)$ & 3.88 & Ref. & Ref. \\
\hline Intrapartum CD $(621,12 \%)$ & 5.09 & $0.10(-1.94$ to 2.15$)$ & $0.50(-0.90$ to 1.90$)$ \\
\hline Vaginal delivery $(156,3 \%)$ & 5.01 & Ref. & Ref. \\
\hline \multicolumn{4}{|l|}{ Group BR (overall) $(7879,4.1 \%)$} \\
\hline Pre-labour CD $(5665,72 \%)$ & 21.08 & $-38.07(-79.31$ to 3.18$)$ & $-27.90(-49.41$ to -6.40$)$ \\
\hline Intrapartum CD (1582, 20\%) & 25.83 & $-33.31(-73.91$ to 7.30$)$ & $-23.85(-44.02$ to -3.67$)$ \\
\hline Vaginal delivery $(632,8 \%)$ & 59.14 & Ref. & Ref. \\
\hline \multicolumn{4}{|l|}{ Group BR (breech) $(7628,4.0 \%) \ddagger$} \\
\hline Pre-labour CD $(5467,72 \%)$ & 20.99 & $-36.75(-77.17$ to 3.67$)$ & $-28.31(-48.76$ to -7.86$)$ \\
\hline Intrapartum CD $(1529,20 \%)$ & 25.64 & $-32.10(-70.86$ to 6.66$)$ & $-24.71(-43.56$ to -4.87$)$ \\
\hline Vaginal delivery $(632,8 \%)$ & 57.74 & Ref. & Ref. \\
\hline \multicolumn{4}{|c|}{ Group preterm BR (breech) $(2512,1.3 \%) \ddagger$} \\
\hline Pre-labor CD (1714, 68\%) & 55.04 & $-93.92(-133.79$ to 54.06$)$ & $-90.49(-133.58$ to -47.40$)$ \\
\hline Intrapartum CD $(566,23 \%)$ & 59.30 & $-89.66(-125.67$ to 53.66$)$ & $-80.36(-121.33$ to -39.39$)$ \\
\hline Vaginal delivery $(232,9 \%)$ & 148.97 & Ref. & Ref. \\
\hline \multicolumn{4}{|c|}{ Group term BR (breech) $(5116,2.7 \%) \ddagger$} \\
\hline Pre-labour CD $(3753,73 \%)$ & 5.43 & $0.61(-2.80$ to 4.02$)$ & $0.88(-2.62$ to 4.37$)$ \\
\hline Intrapartum CD $(963,19 \%)$ & 5.85 & $1.03(-1.98$ to 4.03$)$ & $0.41(-2.69$ to 3.50$)$ \\
\hline Vaginal delivery $(400,8 \%)$ & 4.83 & Ref. & Ref. \\
\hline
\end{tabular}

Continued 
Table 2 Continued

\begin{tabular}{|c|c|c|c|}
\hline \multirow{2}{*}{ 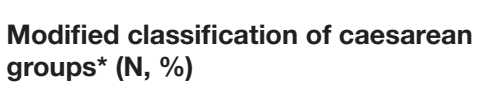 } & \multirow{2}{*}{$\begin{array}{l}\text { WAOS } \\
\text { Mean }\end{array}$} & \multirow{2}{*}{$\begin{array}{l}\text { Unadjusted model } \\
\beta(95 \% \mathrm{Cl})\end{array}$} & \multirow{2}{*}{$\begin{array}{l}\text { Adjusted model† } \\
\beta(95 \% \mathrm{Cl})\end{array}$} \\
\hline & & & \\
\hline \multicolumn{4}{|c|}{ Group BR (transverse or oblique) $(251,0.1 \%)$} \\
\hline Intrapartum CD $(53,21 \%)$ & 31.51 & - & - \\
\hline Vaginal delivery $(0,0 \%)$ & - & - & - \\
\hline Intrapartum CD $(835,18 \%)$ & 32.17 & $2.25(-3.24$ to 7.74$)$ & $-4.89(-8.58$ to -1.19$)$ \\
\hline Vaginal delivery $(1497,31 \%)$ & 29.93 & Ref. & Ref. \\
\hline \multicolumn{4}{|l|}{ Group preterm TW $(3256,1.7 \%)$} \\
\hline Pre-labor CD $(1625,50 \%)$ & 38.10 & $-2.82(10.22$ to 4.58$)$ & $-7.53(-14.62$ to -0.45$)$ \\
\hline Pre-labour CD (682, 37\%) & 40.56 & $5.91(-0.64$ to 12.46$)$ & $-2.55(-8.03$ to 2.93$)$ \\
\hline Intrapartum CD $(346,19 \%)$ & 36.60 & $1.94(-5.00$ to 8.89$)$ & $-0.33(-5.63$ to 4.97$)$ \\
\hline Vaginal delivery $(793,44 \%)$ & 34.66 & Ref. & Ref. \\
\hline \multicolumn{4}{|c|}{ Preterm with first twin in non-cephalic presentation $(1435,0.7 \%)$} \\
\hline Pre-labour CD $(943,66 \%)$ & 36.30 & $-28.78(-65.00$ to 7.43$)$ & $-20.77(-48.26$ to 6.71$)$ \\
\hline Intrapartum CD $(300,21 \%)$ & 42.42 & $-22.67(-55.10$ to 9.77$)$ & $-20.00(-43.06$ to -0.95$)$ \\
\hline Vaginal delivery $(192,13 \%)$ & 65.09 & Ref. & Ref. \\
\hline \multicolumn{4}{|l|}{ Group term TW $(1467,0.8 \%)$} \\
\hline Pre-labour CD $(766,52 \%)$ & 5.15 & $-3.15(-6.44$ to 0.13$)$ & $-1.55(-4.94$ to 1.84$)$ \\
\hline
\end{tabular}

${ }^{*}$ The new labelling system corresponds well with the previous numbering system as follows: 1=NS (Nulliparous, Spontaneous); $2 \mathrm{a}=\mathrm{NI}$ (Nulliparous, Induced); 2b=NC (Nulliparous, Caesarean); 3=MS (Multiparous, Spontaneous); 4a=MI (Multiparous, Induced); 4b=MC (Multiparous, Caesarean); 5=PC (Previous Caesarean); 6,7,9 combined=BR (BReech and other non-cephalic presentation); 8=TW (Twin and other multiple pregnancies); 10=PT (PreTerm).

†Adjusted model: adjusted for a number of potential confounders (online supplementary table S1) wherever appropriate.

$\ddagger$ Transverse and oblique lies were deleted in the regression analysis because these are the hard indication for CD. It should be $100 \%$ CD.

$\mathrm{CD}$, caesarean delivery.

the authors found no difference in long-term neurodevelopmental delay or death. ${ }^{23}$

There is insufficient evidence to evaluate the effects of the planned $\mathrm{CD}$ versus planned vaginal birth on preterm breech presentation, and the optimal mode of delivery of these babies remains controversial. ${ }^{24}$ We found that the adverse perinatal outcome score decreased substantially with prelabour and intrapartum $\mathrm{CD}$, which mainly due to the reduction of neonatal death. Consistent with these findings, a systematic review of seven observational studies concluded that planned CD for preterm breech presentation reduced the risks of neonatal mortality. ${ }^{25} \mathrm{In}$ addition, a recent cohort study also found that intended $\mathrm{CD}$ and emergency $\mathrm{CD}$ were associated with reduced perinatal mortality and morbidity in these women. ${ }^{26}$ The risk of head entrapment may be increased in vaginal delivery, especially before 30 weeks of gestation because the circumference of the head is larger than that of the body. The fetal body can be delivered without full dilation of the cervix, but the aftercoming head may be retained by the cervix. Asphyxia related to difficult delivery has been described after preterm vaginal breech deliveries, and its incidence appears highest before 28 weeks. ${ }^{27}$

Our study also indicates that prelabour CD does not improve maternal and perinatal outcomes in term multiple gestations (95\% were twins), which is consistent with a recent system review. ${ }^{28}$ In contrast, there is increasing evidence for perinatal benefits related to vaginal birth. In a cross-sectional study of 6929 new born infants, non-urgent CD increased the risk of bag 
and mask ventilation ${ }^{29}$ compared with vaginal birth. In a retrospective study of twin births at 37 or more weeks gestation, elective $\mathrm{CD}$ was associated with an increased risk of neonatal transfusion. ${ }^{30}$ Future research should aim to provide evidence on long-term outcomes. ${ }^{28} 31$

Our study further suggests that CD may be a better mode of delivery only for preterm multiple gestations with the first twin in non-cephalic presentation. Literature on this issue is still inconsistent, although most studies failed to show any significant benefit of any particular mode of delivery. ${ }^{32}$ For example, our previous study in 4428 twins found that CD resulted in a lower infant and neonatal mortality when birth weight was between 500 and $749 \mathrm{~g}$. But the beneficial effect of CD disappeared in infants weighing more than $1000 \mathrm{~g} .{ }^{33}$ A Swedish study found no relationship between mode of delivery and perinatal mortality or long-term adverse outcome for twins weighing less than $1500 \mathrm{~g}$. ${ }^{34}$ A recent study also showed that a policy of planned vaginal delivery of very preterm twins with the first twin in cephalic presentation did not increase either severe neonatal morbidity or mortality. ${ }^{35}$ However, none of these studies was prospective; nor did they exclude emergency $\mathrm{CD}$ for various indications. As pointed by Biswas et al, ${ }^{32}$ the inclusion of these unplanned $\mathrm{CD}$ in data analysis potentially skewed the results towards poorer neonatal outcomes in the $\mathrm{CD}$ groups (ie, confounding by indication). ${ }^{32}$ Any benefit conferred by planned $\mathrm{CD}$, therefore, may be nullified. ${ }^{32}$

\section{Strengths and limitation}

The major strength of this study is the large cross-sectional study with clinical data from a contemporary population, which enabled us to examine the relationships between mode of delivery and WAOS in 10 mutually exclusive subgroups and adjust for a number of confounding factors.

It should be noted that even though we selected 19 hospitals across 9 ACOG districts, our study subjects were not a random sample of all births in the USA. Academic institutions were over-represented. Though our weighted preterm birth rate and induction rate were higher than the national average, our overall $\mathrm{CD}$ rate was similar to the corresponding national average $(31.2 \%$ vs $31.1 \%$ in 2006). ${ }^{36}$ Since higher risk women were more likely to undergo a $\mathrm{CD}$, many factors that might affect the association between mode of delivery and WAOS were controlled, but residual confounding is still possible. Second, the data used in this study may be considered a bit outdated, representing deliveries done nearly 10 years ago. However, the Consortium on Safe Labor is still one of the largest and most comprehensive perinatal database so far. The overall CD rate in the USA has not changed substantially over the past decade. ${ }^{37}$ Thus, findings of this study may still be relevant. In addition, Robson classification is a very useful tool with the primary purpose to identify differences in caesarean rates across patient subgroups. However, it does not provide an explanation for these differences or distinguish the specific reason or indication for performing CD. The WAOS has been used to assess the effectiveness of interventions at the hospital level, but we found that it was also a useful indicator when it is used at the individual level. For example, in high-risk women such as preterm birth, the WAOS was much higher than low-risk women (eg, women with spontaneous labour). Finally, this is an observational study. Associations reported in our analysis may not necessarily be causal.

\section{CONCLUSIONS}

In summary, our study suggests that women with repeat $\mathrm{CD}$, term non-cephalic presentation, term twins or other multiple gestation and preterm births may be the potential targets for safely reducing prelabour CD rate, while nulliparas or multiparas with spontaneous or induced labour, women with repeat $\mathrm{CD}$, term non-cephalic presentation, term twins or other multiple gestation and preterm births are potential targets for reducing intrapartum CD rate without compromising maternal and neonatal safety in the USA. On the other hand, CD may still be associated with better perinatal outcomes in women with singleton preterm breech presentation or preterm twins with the first twin in non-cephalic presentation. Allowing labour to continue for a longer period before $6 \mathrm{~cm}$ of cervical dilation and increasing TOLAC rate are suggested approaches. Further clinical trials are needed to make a definitive conclusion on our findings.

\section{Author affiliations}

${ }^{1}$ School of Public Health, Shanghai Jiao Tong University, Shanghai, China ${ }^{2} \mathrm{MOE}$ - Shanghai Key Laboratory of Children's Environmental Health, Xinhua Hospital, School of Medicine, Shanghai Jiao Tong University, Shanghai, China ${ }^{3}$ Intermountain Healthcare and University of Utah, Utah, USA

${ }^{4}$ Christiana Healthcare, Delaware, USA

${ }^{5}$ AVAG and the Amsterdam University Public Health Research Institute, VU University Medical Center, Amsterdam, The Netherlands

${ }^{6}$ National Institute of Heart, Lung and Blood Institute, National Institutes of Health, Maryland, USA

Contributors Study concept and design: JZ. Statistical analysis: J-WZ. Drafting of the manuscript: J-WZ. Critical revision of the manuscript: WB, MH, ADJ, S-HL, JT and JZ. Data collection: JZ, WB, MH and JT.

Funding The Consortium on Safe Labor was supported by the Intramural Research Program of the Eunice Kennedy Shriver National Institute of Child Health and Human Development, National Institutes of Health, through Contract no. HHSN267200603425C. The data analysis was partly supported by a grant from the Shanghai Municipal Health and Family Planning Commission (GWIV-26) and the National Natural Science Foundation of China (81673183).

Competing interests None declared.

Ethics approval The CSL was approved by the institutional review boards of all participating institutions (listed in the funding) and the NIH IRB \#3854 was obtained on $9 / 12 / 2007$.

Provenance and peer review Not commissioned; externally peer reviewed.

Data sharing statement The data that were used in this publication are available on request to the corresponding author.

Open access This is an open access article distributed in accordance with the Creative Commons Attribution Non Commercial (CC BY-NC 4.0) license, which permits others to distribute, remix, adapt, build upon this work non-commercially, and license their derivative works on different terms, provided the original work is 
properly cited, appropriate credit is given, any changes made indicated, and the use is non-commercial. See: http://creativecommons.org/licenses/by-nc/4.0/.

\section{REFERENCES}

1. Martin JA, Hamilton BE, Osterman MJ, et al. Births: final data for 2013. Natl Vital Stat Rep 2015;64:1-65.

2. BaJ GL, Lauer JA, Betran AP, et al. The global numbers and costs of additionally needed and unnecessary caesarean sections performed per year: overuse as a barrier to universal coverage. World Health Report Background Paper: Background Paper 2010.

3. Lumbiganon P, Laopaiboon M, Gülmezoglu AM, et al. Method of delivery and pregnancy outcomes in Asia: the WHO global survey on maternal and perinatal health 2007-08. Lancet 2010;375:490-9.

4. Villar J, Valladares E, Wojdyla D, et al. Caesarean delivery rates and pregnancy outcomes: the 2005 WHO global survey on maternal and perinatal health in Latin America. Lancet 2006;367:1819-29.

5. Ye J, Betrán AP, Guerrero Vela M, et al. Searching for the optimal rate of medically necessary cesarean delivery. Birth 2014;41:237-44.

6. Molina G, Weiser TG, Lipsitz SR, et al. Relationship Between Cesarean Delivery Rate and Maternal and Neonatal Mortality. JAMA 2015;314:2263-70.

7. Zhao Y, Zhang J, Hukkelhoven C, et al. Modest Rise in Caesarean Section from 2000-2010: The Dutch Experience. PLoS One 2016;11:e0155565.

8. Bouvier-Colle MH, Mohangoo AD, Gissler M, et al. What about the mothers? An analysis of maternal mortality and morbidity in perinatal health surveillance systems in Europe. BJOG 2012;119:880-90.

9. de Jonge A, Baron R, Westerneng $\mathrm{M}$, et al. Perinatal mortality rate in the Netherlands compared to other European countries: a secondary analysis of Euro-PERISTAT data. Midwifery 2013;29:1011-8.

10. Robson MS. Can we reduce the caesarean section rate? Best Pract Res Clin Obstet Gynaecol 2001;15:179-94.

11. Zhang J, Troendle J, Reddy UM, et al. Contemporary cesarean delivery practice in the United States. Am J Obstet Gynecol 2010;203:326.e1-326.e10.

12. Martin JA, Hamilton BE, Sutton PD, et al. Births: final data for 2004. Natl Vital Stat Rep 2006;55:1-101.

13. Mann S, Pratt S, Gluck P, et al. Assessing quality obstetrical care: development of standardized measures. Jt Comm J Qual Patient Saf 2006;32:497-505.

14. Torloni MR, Betran AP, Souza JP, et al. Classifications for cesarean section: a systematic review. PLoS One 2011;6:e14566.

15. Zhang J, Geerts C, Hukkelhoven C, et al. Caesarean section rates in subgroups of women and perinatal outcomes. BJOG 2016;123:754-61.

16. Db. R. Multiple imputation for nonresponse in surveys. New York: John Wiley, 1987.

17. Sabol B, Denman MA, Guise JM. Vaginal birth after cesarean: an effective method to reduce cesarean. Clin Obstet Gynecol 2015;58:309-19.

18. Landon MB. Vaginal birth after cesarean delivery. Clin Perinatol 2008;35:491-504.
19. Guise JM, Eden K, Emeis C, et al. Vaginal birth after cesarean: new insights. Evid Rep Technol Assess 2010;191:1-397.

20. Zhang J, Landy HJ, Branch DW, et al. Contemporary patterns of spontaneous labor with normal neonatal outcomes. Obstet Gynecol 2010;116:1281-7.

21. American College of Obstetricians and GynecologistsSociety for Maternal-Fetal Medicine. Obstetric care consensus no. 1 : safe prevention of the primary cesarean delivery. Obstet Gynecol 2014;123:693-711.

22. Berhan $Y$, Haileamlak $A$. The risks of planned vaginal breech delivery versus planned caesarean section for term breech birth: a metaanalysis including observational studies. BJOG 2016;123:49-57.

23. Hofmeyr GJ, Hannah M, Lawrie TA. Planned caesarean section for term breech delivery. Cochrane Database Syst Rev 2015:CD000166.

24. Alfirevic Z, Milan SJ, Livio S. Caesarean section versus vaginal delivery for preterm birth in singletons. Cochrane Database Syst Rev 2013:CD000078.

25. Bergenhenegouwen LA, Meertens LJ, Schaaf J, et al. Vaginal delivery versus caesarean section in preterm breech delivery: a systematic review. Eur J Obstet Gynecol Reprod Biol 2014;172:1-6.

26. Bergenhenegouwen L, Vlemmix F, Ensing S, et al. Preterm Breech Presentation: A Comparison of Intended Vaginal and Intended Cesarean Delivery. Obstet Gynecol 2015;126:1223-30.

27. Bodmer B, Benjamin A, McLean FH, et al. Has use of cesarean section reduced the risks of delivery in the preterm breech presentation? Am J Obstet Gynecol 1986;154:244-50.

28. Hofmeyr GJ, Barrett JF, Crowther CA. Cochrane Pregnancy and Childbirth Group. Planned caesarean section for women with a twin pregnancy. Cochrane Database Syst Rev 2015;115.

29. de Almeida MF, Guinsburg R, da Costa JO, et al. Non-urgent caesarean delivery increases the need for ventilation at birth in term newborn infants. Arch Dis Child Fetal Neonatal Ed 2010;95:F326-F330.

30. Suzuki S, Inde Y, Igarashi M, et al. Elective cesarean as a risk factor for transfusion after delivery of twins. J Nippon Med Sch 2008;75:247-9.

31. Seelbach-Goebel B. Twin Birth Considering the Current Results of the "Twin Birth Study". Geburtshilfe Frauenheilkd 2014;74:838-44.

32. Biswas A, Su LL, Mattar C. Caesarean section for preterm birth and, breech presentation and twin pregnancies. Best Pract Res Clin Obstet Gynaecol 2013;27:209-19.

33. Zhang J, Bowes WA, Grey TW, et al. Twin delivery and neonata and infant mortality: a population-based study. Obstet Gynecol 1996;88:593-8

34. Rydhström H. Prognosis for twins with birth weight less than 1500 gm: the impact of cesarean section in relation to fetal presentation. Am J Obstet Gynecol 1990;163:528-33.

35. Sentilhes L, Oppenheimer A, Bouhours A-C, et al. Neonatal outcome of very preterm twins: policy of planned vaginal or cesarean delivery. Am J Obstet Gynecol 2015;213:73.e1-73.e7.

36. Martin JA, Kung HC, Mathews TJ, et al. Annual summary of vital statistics: 2006. Pediatrics 2008;121:788-801.

37. Martin JA, Hamilton BE, Osterman MJ. Births in the United States, 2015. NCHS Data Brief 2016;258:1-8. 